\title{
Author Correction: Streamlined hydrogen production from biomass
}

Ping Zhang, Yan-Jun Guo, Jianbin Chen (D), Yu-Rou Zhao, Jun Chang, Henrik Junge (D), Matthias Beller (i) and Yang Li(D)

Correction to: Nature Catalysis https://www.nature.com/articles/s41929-018-0062-0, published online 30 April 2018.

In the version of this Article originally published, formaldehyde $\left(\mathrm{CH}_{2} \mathrm{O}\right)$ was not identified alongside the main product, formic acid. Formaldehyde previously was not observed due to $\mathrm{H}_{2} \mathrm{O}$ resonance in the ${ }^{1} \mathrm{H}$ NMR spectrum. The presence of $\mathrm{CH}_{2} \mathrm{O}$ has now been confirmed by ${ }^{1} \mathrm{H}$ NMR and ${ }^{13} \mathrm{C}$ NMR in $d_{6}$-DMSO. These results are shown in Supplementary Fig. 5 ; in which panels b and c have been added to show the presence of $\mathrm{CH}_{2} \mathrm{O}$.

The KIE studies were then conducted with the addition of $\mathrm{CH}_{2} \mathrm{O}$, in the form of paraformaldehyde. This addition has no influence on the previous conclusion that decarboxylation is involved in the RDS. In Table 3, the 'Reaction solution' column now lists $\mathrm{CH}_{2} \mathrm{O}$ as an additional additive in each reaction solution. Footnote a now also includes "paraformaldehyde, $6.6 \mathrm{mg}, 0.21 \mathrm{mmol}$, dissolved in the reaction mixture".

An additional experiment in the presence of $\mathrm{CH}_{2} \mathrm{O}$ (paraformaldehyde was added and dissolved in the reaction mixture) was conducted to investigate the effect of each component in the reaction mixture after the hydrolysis-oxidation step on the production of $\mathrm{H}_{2}$, and added as new entry 9 in Supplementary Table 6. Notably, no significant influence on the catalyst performance was observed in the presence of $\mathrm{CH}_{2} \mathrm{O}$ (4 mol\%). In Fig. 4, "CH $\mathrm{H}_{2} \mathrm{O}$ " has been added after "HOAc" in the list of chemicals shown in green.

In the sentence "First, the analysis of the liquid phase..., " $\mathrm{CH}_{2} \mathrm{O}(4 \mathrm{~mol} \%$, exists as methanediol)" has been added to the list of chemicals in the liquid phase. In the sentence "No significant influence on the catalyst ..., " $\mathrm{CH}_{2} \mathrm{O}$ " has been added to the list of chemicals present, and "entries 6-8" has been changed to "6-9". Furthermore, "Supplementary Table 6, entries 9 and 10 " has been replaced with "Supplementary Table 6, entries 10 and 11".

Published online: 5 August 2019

https://doi.org/10.1038/s41929-019-0337-0 